\title{
PROSES PELAKSANAAN RITUAL KAKADIUNO BUKUNO KAMOKULANO LIWU PADA MASYARAKAT BOMBONAWULU DI KELURAHAN BOMBONA WULU KECAMATAN GU KABUPATEN BUTON TENGAH
}

\author{
${ }^{1) *}$ Nurdin, ${ }^{2)}$ La Niampe, dan ${ }^{3)}$ Syahrun \\ Program Studi Kajian Budaya Pascasarjana Universitas Halu Oleo, KendariJurusan \\ Jurusan Tradisi Lisan Fakultas Ilmu BudayaUniversitas Halu Oleo, Kendari \\ Jurusan Arkeologi Fakultas Ilmu Budaya Universitas Halu Oleo, Kendari
}

Koresponding Author:*Nurdin (nurdin.seny@gmail.com)

\begin{abstract}
Abstrak: Tujuan penelitian ini adalah untuk mengkaji dan mendeskripsikan proses ritual kakadiuno Bukuno kamokulano liwu pada masyarakat Bombonawulu Kecamatan $\mathrm{Gu}$ Kabupaten Buton Tengah. Penelitian menggunakan metode kualitatif dengan penyajiannya dalam bentuk deskripsi. Lokasi penelitian ini berada di Kelurahan Bombonawulu Kecamatan Gu Kabupaten Buton Tengah. Pengumpulan data dilakukan dengan wawancara, observasi dan dokumentasi.Dalam penelitian ini, penulis menggunakan teknik analisis data kualitatif. Hasil dalam penelitian ini menunjukkan bahwa proses pelaksanaan ritual kakadiu Bukuno kamokulano liwuterdiri atas lima tahap yakni : (1) tahap persiapan meliputi penyiapan kelengkapan ritual kakadiu Bukuno kamokulano liwusekaligus mengecek kelengkapan ritual di Istana Daduwali; (2) tahap menuju tempat persemayamanBukuno kamokulano liwu, meliputi: iringiringanpejabat pelaksana ritual maupun rombongan dari kaum laki-laki, lalu rombongan kaum perempuandan pembawa bendera hitam, pejabat-pejabat pelaksana ritual maupun rombongan dari kaum laki-laki, lalu rombongan kaum perempuan dan pembawa bendera bendera putih; (3) tahap di tempat persemayaman, meliputi : melakukan sembah, membersihkan diri, memanjat tebing, menyembah kembali dan dilanjutkan membuka penutup yang membungkus rangka Bukuno kamokulano liwu, (4) tahap memandikan, meliputi : mengkremasi rangka dengan santan kelapa, lalu mengolesi dengan minyak kelapa dan menyirami tulang dengan air suci Oe ngkolaki; (5) tahap haroa, meliputi: pembacaan doa selamat dan makan bersama.
\end{abstract}

Kata kunci: Pelaksanaan, Ritual, Kakadiu, Bukuno, Kamokulano, Liwu

Abstract: The purpose of this study is to study and describe the kakadiu Bukuno kamokulano liwu ritual process in Bombonawulu community, Gu District, Buton Tengah Regency. The study uses qualitative methods by presenting them in the form of descriptions. The location of this research is in Bombonawulu Village, Gu District, Central Buton Regency. Data collection with interviews, observations and documentation. This study, the authors used qualitative data analysis techniques. The results of this study indicate that the process of carrying out the kakadiu Bukuno kamokulano liwu ritual consists of five stages, namely: (1) the preparatory stage includes the preparation of the complete kakadiu Bukuno kamokulano liwu ritual as well as checking the completeness of the ritual at the Daduwali Palace; (2) the steps to the Bukuno kamokulano liwu burial place, including: the procession of ritual executives, starting with the black flag bearer, the ritual executor and the group of 
men, then the group of women and white flag bearers,(3) stages in the dwelling place, including: doing worship, cleaning themselves, climbing the cliff, worshiping again and continuing to open the cover that wraps the Bukuno kamokulano liwu frame and (4) the bathing stage, includes: scraping the frame with coconut milk, then smearing it with coconut oil and water the bones with holy water ngkolaki, (5) haroa stage, including: reading congratulations and eating together.

Keywords: Implementation, Ritual, Kakadiu, Bukuno, Kamokulano, Liwu

\section{PENDAHULUAN}

Di era globalisasi dan modernisasi sekarang ini, kehidupan manusia semakin beragam. Budaya terus menerus mempengaruhi dan dipengaruhi oleh perkembangan pola pikir dan cara bertindak manusia dalam kehidupan. Perkembangan budaya ada yang berlangsung cepat (revolusi kebudayaan) dan ada pula yang berkembang perlahan (evolusi kebudayaan). Masyarakat Indonesia adalah masyarakat majemuk yang ditandai adanya kesatuan sosial yang memiliki perbedaan latar belakang yang beragam, seperti suku bangsa, agama atau kepercayaan, adat istiadat dan budaya.

Kepercayaan tradisional tersebut sudah ada sejak dahulu kala dan telah menyatu hingga sulit untuk dilepaskan, bahkan sebelum ada penyebaran agama besar seperti Islam dan Kristen. Kepercayaan tradisonal tersebut sampai saat ini masih dilestarikan dan dijumpai misalnya sunda wiwita di kelompok masyarakat Sunda, kejawen oleh masyarakat Jawa, merapu di Pulau Sumba, ugamo malim Suku Batak dikawasan danau Toba dan kaharingan pada Suku Dayak ( https://www.goodnewsfromindonesia.id/ 2017/05/5-agama-asli-leluhur-indonesiayang-menjadi-bukti-keberagaman diakses tanggal 6 Oktober 2019).

Setiap daerah mempunyai kebudayaan yang berbeda-beda, di mana kebudayaan tersebut telah menjadi ciri khas yang membedakan antara satu dengan yang lainnya.Masyarakat Bombonawulu juga memiliki kepercayaan terhadap Ketuhanan yang mereka namai

Kawasanoumpu. Selain Kawasanoum, masyarakat Bombonawulu juga mempercayai adanya Wali sebagai pesuruh Kawasanoumpu di muka bumi. Wali adalah makluk halus, suci yang tak tampak dan tak dapat dijangkau. Mereka hidup ditempat - tempat suci atau di tempat -tempat yang jauh dari jangkauan manusia biasa (La Ode Dika, 1971).

Manusia Beteno ne wulu adalah manusia yang dipercaya lahir dari sebatang bambu kuning dan ditemukan dalam rumpun bambu kuning yang berada di wilayah kekuasaan Sangiya Daduwali. Selain proses kelahirannya yang berbeda dengan manusia pada umumnya, masyarakat Bombonawulu mempercayai pula bahwa manusia Beteno ne wulu mempunyai kemampuan bersahabat dengan para Wali. Maka, untuk mencapai alam para wali tersebut, masyarakat Bombonawulu melaksanakan ritual kakadiu Bukuno kamokulano liwu.

Kakadiu Bukuno kamokulano liwu (manusia Beteno ne wulu), bila diterjemahkan kedalam bahasa Indonesia, bermakna ritual memandikan rangka (tulang) pemimpin negeri Pancana. Kebiasaan memandikan rangka manusia Beteno ne wulu ini menjadikan tradisi turun- temurun yang masih dilaksanakan sampai saat ini oleh masyarakat 
Bombonawulu Kecamatan Gu Kabupaten Buton Tengah dilaksanakan setiap tiga tahun sekali. Seiring dengan kemajuan peradaban umat manusia dan kemajuan teknologi yang semakin canggih saat ini, tidak membuat ritual Kakadiu Bukuno kamokulano tergeser justru masih bertahan serta dilestarikan oleh masyarakat sampai saat ini. Berdasarkan latar belakang tersebut, maka peneliti tertarik untuk mengkajinya dalam penelitian dengan judul “ Proses Pelaksanaan Ritual Kakadiu Bukuno kamokulano liwu Pada Masyarakat Bombonawulu Kecamatan Gu Kabupaten Buton Tengah Provinsi Sulawesi Tenggara".

\section{METODE PENELITIAN}

Penelitian tentang tuturan ritual "Kakadiu Bukuno kamokulano liwu" pada masyarakat Bombonawulu, Kecamatan $\mathrm{Gu}$, Kabupaten Buton Tengah, merupakan jenis penelitian kepercayaan tradisional yang menggunakan metode kualitatif dan teknik analisis deskriptif-kulaitatif yang berusaha memahami menafsirkan suatu peristiwa dalam situasi tertentu menurut perspektif peneliti.Pendekatan penelitian menggunakan pendekatan kualitatif. Pendekatan kualitatif menekankan keadaan sebenarnya dari suatu objek yang terkait langsung dengan konteks dan waktu yang menjadi perhatian peneliti. Peneliti akan mengamati, mewawancarai dan menangkap dari dunia realitas mengenai tuturan ritual KakadiuBukuno kamokulano liwu Pada Masyarakat Bombonawulu Kecamatan $\mathrm{Gu}$ Kabupaten Buton Tengah Provinsi Sulawesi Tenggara".

Penelitian ini dilaksanakan di wilayah administrasi Kelurahan Bombonawulu Kecamatan Gu, Kabupaten Buton Tengah. Daerah ini dipilih sebagai lokasi penelitian didasarkan beberapa pertimbangan : (1) Kelurahan Bombonawulu, Desa Wakeakea dan Desa Walando tempat bermukimnya masyarakat Pancana yang masih menyelenggarakan ritual kakadiu Bukuno kamokulano liwu, kebiasaan ini dilakukan oleh masyarakat Pancana sejak zaman dahulu kala sebelum adanya pengaruh Hindu dan Islam di Bombonawulu; (2) ritual kaka Biu Bukuno kamokulano liwu ini merupakan salah satu tradisi kepercayaan masyarakat Bombonawulu yang diwariskan secara turun temurun kemudian masih dipertahankan keberadaannya dan dilaksanakan ritualnya setiap tiga tahun sekali di Kantoto wilayah administrasi Kelurahan Bombonawulu Kecamatan Gu Kebupaten Buton Tengah.

Jenis data dalam penelitian ini adalah kualitatif. Data kualitatif yang dimaksud dalam arti menekankan pada pemahaman interpretasi dan pendapat seseorang yang didapat dari hasil wawancara lapangan dan hasil observasi lapangan. Selanjutnya data kualitatif dalam penelitian ini merupakan data pelengkap, baik berupa angka-angka, penjumlahan, maupun statistik yang berhubungan dengan monografi, badan pusat statistik dan sumber lain yang diperoleh di kantor pemerintah setempat.

Data yang diperlukan dalam penelitian ini adalah prosespelaksanaan ritual kakadiu Bukuno kamokulano liwu. Sasaran penelitian yang diteliti adalah tokoh adat, tokoh masyarakat, tokoh agama, pejabat pemerintah atau masyarakat lainnya yang mengikuti pelaksanaan ritual kakadiu Bukuno kamokulano liwu pada masyarakat Bombonawulu Kecamatan Gu Kabupaten Buton Tengah.

Berdasarkan sumbernya,data dalam sebuah penelitian dibagi menjadi 
dua kategori yaitu data primer dan data sekunder. Data primer adalah data yang langsung diperoleh dari lokasi penelitian dan berkaitan erat dengan masalah penelitian. Maksudnya, para informan yang terlibat langsung atau melihat langsung dari seluruh rangkaian kegiatan proses pelaksanaan ritual kakadiu Bukuno kamokulano liwu pada masyarakat Bombonawulu Kecamatan Gu Kabupaten Buton Tengah. Informan yang dimaksud adalah tokoh masyarakat, tokoh agama, pejabat pemerintah maupun pembaca doa serta masyarakat setempat. Sedangkan, data sekunder adalah data yang diperoleh dari hasil penelitian orang lain atau sumber informasi lainnya, yang relevan dengan permasalahan dalam penelitian ini yang telah dipublikasikan. Penentuan informan dalam penelitian ini dilakukan sesuai kebutuhan penelitian, metode penentuan informan dilakukan dengan teknik purposif (informan sudah diketahui) sesuai maksud dan tujuan penelitian. Dalam teknik purposif ditentukan jumlah orang yang akan diwawancarai, apabila belum memadai, peneliti akan menentukan kembali informan selanjutnya.

Instrumen yang digunakan dalam penelitian ini adalah (1) Observasi.Observasi dilakukan dengan teknik observasi partisipasi atau pengamatan terlibat. Namun keterlibatan peneliti hanya sebatas pada kegiatan kegiatan yang berkaitan dengan fokus kajian atau pokok masalah penelitian (Garna, 1999 :63); (2) Wawancara. Dalam melakukan wawancara peneliti menggunakan pedoman wawancara. Peneliti melakukan wawancara informan yang melakukan ritual (informan kunci) diantaranya : La Anggu, Muhamad Syafei Alias La Onu, La Yimpi serta tokoh adat lainnya yang memuat pokok - pokok pertanyaan sesuai dengan permasalahan penelitian;

Dokumentasi. Dokumenentasi yang diperlukan dalam penelitian ini adalah dokumen tentang proses pelaksanaan ritual kakadiu Bukuno kamokulano liwu, foto, kliping media massa, dan arsip desa.

Penelitian ini, penulis menggunakan teknik analisis data kualitatif. Data kualitatif yang dimaksud adalah berupa catatan dan pemaknaan terhadap dokumen serta berupa keterangan dari informan. Untuk menganalisis data yang diperoleh, maka langkahlangkah yang dilakukan dalam menganalisis data adalah pertama, reduksi data. Pada tahap reduksi data, peneliti akan memilah secara teliti data yang didapat di lapangan. Langkahlangkah yang digunakan pada tahap ini, sebagai berikut :(1) mengumpulkan data jumlah penduduk masyarakat Kelurahan Bombonawulu. (2) mengumpulkan data tentang proses pelaksanaan ritual kakadiu Bukuno kamokulano liwu. Kedua, penyajian data. Penyajian data dilakukan dengan mendeskripsikan hasil temuan dari kegiatan wawancara terhadap informan. Langkah-langkah yang digunakan pada tahap ini sebagai berikut :(1) mencari informasi tentang proses pelaksanaan ritual kakadiu Bukuno kamokulano liwu, (2) mendeskripsikan pelaksanaan upacara kakadiu Bukuno kamokulano liwu. (3) menganalisis proses pelaksanaan ritualkakadiu Bukuno kamokulano liwu.

Penyajian hasil analisis data formal adalah disajikan dalam bentuk tabel, bagan, atau gambar tentang ritual kakadiu Bukuno kamokulano liwu dalam upacara adat masyarakat Bombonawulu dengan cara mendiskusikan, memberikan penafsiran serta interprestasi. 


\section{PEMBAHASAN}

Proses Ritual kakadiuno Bukuno kamokulano liwu.

\section{Pertama, Tahap Persiapan}

Menurut Wahjono (dalam

Pujiastuti, 2011: 203) dalam sebuah upacara terdapat berbagai sajian atau sesaji yang merupakan salah satu unsur religi sesaji kepada kekuatan gaib tersebut pada umumnya berfungsi sebagai sesembahan. Dalam interaksi sosial, persembahan berfungsi sebagai instrumen untuk mengukuhkan hubungan antara si pemberi dan si penerima, yang kemudian dikokohkan lagi dengan suatu pemberi balasan. Semua unsur kecil tersusun dalam suatu sajian mengandung makna atau pesan tersebut menyatakan apa yang ingin dikomunikasikan oleh manusia kepada kekuatan gaib yang dimaksud. Berdasarkan wawancara penulis dengan informan Muhamad Syafei mengatakan bahwa pertama-tama kalau kita pergi hari Jum'at, pada hari Kamis harus terlebih dahulu menyediakan kelengkapan ritual. Misalnya, ayam dan lain-lain.Untuk lebih jelasnya dapat dilihat dalam kutipan wawancara di bawah ini.

" do kalaiye oleo no duma. jadio hamisi dobalandomo, dedodoane manu, ano'a dofontantane dua seulu manu, Bahi Bahino dowae se daduwali, Bahao naewina siapumo da kumandiue, jadi padamo doalaie dawunoa, dokalomo" (wawancara, 14 Desember 2019)

Terjemahan:

"Pertama tama kalau kita pergi hari Jum'at, hari kamisnya kita belanja kelengkapan ritual seperti ayam dan lainya.Malam nya di daduwali berdoa supaya pada esok hari Jum'at siap berangkat ketempat persemayaman tulang".
Pendapat informan di atas, dipertegas dengan informan Wa Duma mengatakan hal yang sama sebagaimana diungkapkan oleh informan lainnya di atas. Hal ini dapat dilihat pada kutipan wawancarannya di bawah ini.

"Ho Bine ho Bine. tao kanu kampana'a se galampano daduwali maicu, no pohato hatomoa saha'a ibaha nia no lengapumoa dokalamo sebuku sepimpi maicu"(wawancara, 13 Desember 2019).

Terjemahan:

"Kami perempuan, menyediakan isi kampana'a dari Galampano daduwali, setelah pajabat Saha dan Hukumu lengkap baru kami pergi ke tebing persemayaman Bukuno kamokulano Liwu”.

Berdasarkan pernyataan kedua informandiatas, menegaskan bahwa setiap hajatan upacara ritual kakadiu Bukuno kamokulano liwudi Ombonowulu selalu dimulai dari Galampano Daduwali ( istananya para Sugi). Adapun persiapan dalam ritual kakadiu Bukuno kamokulano liwu ini, dimulai dari : (1) penyiapan segala keperluan yang berkaitan dengan pelaksanaan ritual disiapkan di hari Kamis atau sehari sebelum pelaksanaan ritual dimulai. (2) pada malam harinya (malam Jum'at) salah satu pejabat memasuki rumah Daduwali untuk berdoa agar pelaksanaan ritual berjalan dengan aman dan tertib. (3) pagi harinya, tepatnya hari Jum'at pagi seluruh pejabat adat dari golongansaha dan golongan hukum serta saha ho Bine berkumpul di Galampono Daduwalisebelum berangkat menuju tempat persemayaman Bukuno kamokulano liwu. 


\section{Kedua, Tahap Menuju Tempat Persemayaman}

Pelaksanaan tahap menuju tempat persemayaman ini dilaksanakan setelah kegiatan di Galampano Daduwali selesai. Peserta yang hadir dalam pelaksanaan ritual ini adalah pejabat adat dari Bisa, pejabat adat imamu, pejabat adat Bonto serta rombongan laki laki lainnya, setelah rombongan laki laki, disusul rombongan perempuan dimulai dari istri pejabat adat Bisa, istri pejabat imamu, istri pejabat Bonto dan perempuan lainnya. Untuk lebih jelasnya dapat dilihat dari kutipan wawancara penulis dengan informan $\mathrm{La}$ Anggu, di bawah ini.

"Babaono mainduluno tewise
meintanono tombi, mangka
noangkafi ganda, mbololo, angka tombi kapute wekundo. Manusiamo doangkafimo ganda, Bisa'o poangkafi Be Imamu mangkao Bonto.Pada engkena'a ho Bineno Bisa noangkafie hoBineno imamu .dopoangkangkafi ho Bineno Bonto, ho Bineno pahaBela, ho Bineno Waci, ho Bineno Tongkoisa" (wawancara, 12 Desember 2019).

Terjemahan:

"Pertama atau di depan rombongan pemegang bendera hitam, lalu yang bawah gendang dan gong, lalu pejabat adat dariBisa, pejabat adatimam, pejabat adatBonto serta rombongan laki -laki lainnya, setelah rombongan laki-laki, disusul rombongan perempuan dimulai dari istri pejabat adat Bisa, istri pejabatimam, istri pejabat Bonto dan perempuan lainnya. Terakhir sebagai penutup rombongan adalah pembawa bendera putih"

Dari ungkapan yang disampaikan oleh informan di atas, maka iring-iringan rombongan menuju tempat persemayaman di tebing Kantoto, dimulai dari urutan paling di depan yakni : (1) pembawa bendera hitam, (2) pembawa gong dan gendang/beduk, (3) pejabat dari golongan saha yakni Bisa, (4) pejabat dari golongan hukumuimam, (5) pejabat dari golongan saha Bonto dan pejabat adat lainnya serta rombongan dari laki-laki lainnya. (6) rombongansaha hoBine dimulai dari istrinya Bisa, istri imamu, sambil membawa kampana'a sebagai persembahan, lalu istri pejabat Bonto dan rombongan perempuan lainnya dan (7) pembawa bendera putih sebagai penutup. Selama dalam perjalanan gendang/bedug dan gong dipukul berulang kali sehingga mengeluarkan bunyi. Hal ini sesuai dengan pendapat Koentjaraningrat (1992 : 221) menjelaskan bahwa dalam setiap sistem upacara keagamaan terkandung lima aspek yakni: (1) tempat upacara, (2) waktu pelaksanaan upacara, (3) bendabenda dan peralatan upacara, (4) orang yang melakukan atau memimpin jalannya upacara, dan (5) orang-orang yang mengikuti jalannya upacara.

\section{Ketiga, Tahap di Tempat Persemayaman \\ Pada tahap di tempat} mengucapkan sembah sebanyak 4 kali sambil diikuti gerakan menundukkan kepala kebawah bersamaan dengan kedua tangan sambil berucap “ somba waopu ia жаори ", kemudian dilanjutkan dengan pejabat pelaksana maupun bukan yang hendak naik di atas tebing mencuci kedua kaki, tangan serta muka. Selanjutnya, dalam prosesi tersebut, Bisa menyebut raja -raja dan melakukan sembah sebagai bentuk penghormatan kepada pemimpin negeri atau ungkapan rasa kecintaan pada pemimpin negeri yang telah memimpin negeri Pancana/Ombonowulu. Hal ini dipertegas dengan pernyataan informan 
La Angguseperti dalam kutipan wawancaranya dibawah ini :

" neacino de kadiu Bukuku maicu do sambili kamai aondo :" Beteno newulu Beteno ne kau Bangka, Beteno ne Tolisi Beteno ne Sahu, Beteno ne tongkoa.a, pada engkena'ado kangkonamo neano, raja Lao de Rahmani, raja Lao de Sawerigadi Lagadi, mangka neano raja Lao de Mbalitawa Beheteno ne wulu neanoa Sangiyano Daduwali hoBineno neanoa Wao de Suali dunia Beteno ne kaBangka Bangka Be Wao de Kulipopota no mai te Bidadahi, padaha aicudo sambilimo ananondo sa sa Sugi Alitae, Sugi La Ende, Sugi Patani, Sugi Ntololo, Sugi Mpalola, Sugi Aerwondo,Sugi Patola,Sugi Ambona, Sugi Manuru pada dokangkona neando maicu do kangkonamo sambilimo fekanandono alamu " ntaodi mefekanandono dunia nimefekanandono alamu, mekanandono bawangi, mekandondono umaci, allah ta,ala rasulullah adamu Muhamad, pada aicu do sombamo:" Somba kita waopuia ia waopu " pada dosamba'adofonimo te wawo, dohato te wawo dosambamo dua fatopaku, Sombah maicu. ma'ana noa, carano do somba raja". raja ntaodi Ombonowulu ni"

(wawancara, 12 Desember 2019).

Dari ungkapan informan di atas, menegaskan bahwa proses yang dilakukan saat berada ditempat persemayamanBukuno kamokulano liwu ditebing kantoto adalah (1) pejabat Bisa duduk di atas kedua lipatan kakinya, lalu berniat (Batata) menyebut raja-raja Ombonowulu atau Pancana pada zaman Hindu dimulai dari raja La Rahmani, raja La Sawerigadi Lagadi, raja Laode Mbalitawa Beteno Ne wulu Alias Sangiya
Daduwali, kemudian raja rajasugi dimulai dari Sugi La Alitae, Sugi La Ende, Sugi Patani, Sugi Ntalolo, Sugi Mpalola, Sugi Aerwondu, Sugi Patola, Sugi Ambona dan terakhir Sugi Manuru. (2) mengucapkan sembah sebanyak 4 kali sambil diikuti gerakan menundukkan kepala kebawah bersamaan dengan kedua tangan sambil berucap " somba waopu ia waори " (3) pejabat pelaksana maupun bukan yang hendak naik di atas tebing mencucui kedua kaki, tangan serta muka. (4) memanjat tebing guna mencapai tempat persemayaman Bukuno kamokulano liwu. Dalam prosesi tersebut, Bisa menyebut raja-raja dan melakukan sembah sebagai bentuk penghormatan kepada pemimpin negeri atau ungkapan rasa kecintaan pada pemimpin negeri yang telah memimpin negeri Pancana / Ombonowulu. Hal ini sejalan apa yang dikemukakan oleh Baal (dalam

Koentjaraningrat,1992:219)upacara keagamaan biasanya dijadikan wahana oleh manusia untuk berkomunikasi dengan mereka yang disembah, dan upacara bersaji katanya adalah sistem simbol untuk berkomunikasi.

\section{Keempat, Tahap Menyemayamkan Bukuno Kamokulano Liwu}

Memasuki

tahap

menyemayamkan Bukuno kamokulano liwu ada beberapa yang harus dilakukan diantaranya memandikan dimulai dari kepala, pertama-tama dikeremasi dengan santan kepala, lalu diolesi dengan minyak kelapa, sesudah itu imam menyiramkan air suci ŏe ngkolaki sebanyak 3 x dari kepala hingga ke kaki. Selanjutnya, dibungkus dengan kain putih atau dikafani, lalu dibacakan doa oleh seorang imam yang ditunjuk, kemudian kembali ke Daduwali. Hal ini sesuai dengan pendapatnya informan Wa Duma dalam 
kutipan wawancaranya mengatakan seperti di bawah ini.

"do fokadiu do mulai te focuno,tolupaku do sampuae, dokadiu'e BaBano o santa, mangka mina , pada do kadiue do waluemo dua iBaha mite mate nia, do umpuno pa'a limando, . jadido sinimo mie mate baru maicu hae emoa. padado kadiue do waluemo dua iBaha mie mate nia, do umpuno pa'alimando, jadi do sinimo mie mate baru maicu hae emoa. Kawuluno Be Baduno dua, toluBoke dua pa'a kaBokeno.padado kawuluae do pasapane kacucuBinoa .pada aicu de basenomo doa , pada de Basa doa,do awomo se daduwali maicua" (wawancara, 12 Desember 2019)

Terjemahan:

"Memandikan dimulai dari kepala,pertama dikremasi dengan Santan kelapa, lalu diolesi dengan minyak kelapa, sesudah itu imam menyiramkan air suci oe ngkolaki sebanyak 3 kali dari kepala hingga ke kaki. Sesudah itu dibungkus dengan kain putih atau dikafani, lalu dibacakan doa imam, kemudian kembali ke Daduwali”.

Dari penyampaian informan di atas, bahwa dalam menyemayamkan Bukuno kamokulano liwu, harustempatnya di atas tebing dan dalam goa, tulang Bukuno kamokulano liwu terbungkus dengan kain putih atau kain kafan yang disimpan dalam sebuah perahu dan penutupnya dari perahu juga, lalu diberi kulambu. Untuk menyemayamkan Bukuno kamokulano liwu, ada beberapa proses kegiatan, dimulai dari : (1) membuka penutup Bukuno kamokulano liwu dari perahu, (2) mengangkat dan memindahkan tulang dari tempatnya dari perahu ke penutup tulang yang juga dari perahu, (3) membuka pembungkus tulang dari kain putih / kain kafan, mengkremasiBukuno kamokulano liwu dari tengkorak kepala hingga kaki dengan santan oleh petugas pelaksanasaha hoBine (istri pejabat Bisa dan istri pejabat imamu), (5) mengolesi Bukuno kamokulano liwu dari tengkorak kepala hingga kaki dengan minyak kelapa oleh petugas saha hoBine (istri pejabat Bisa dan istri pejabat imamu, (6) sesudah dikremasi dengan santan dan minyak kelapa, lalu pejabat imam menyiramkan air suci oe ngkolaki dari kepala hingga kaki sebanyak 3 kali, (7) pejabat Imamu dan pejabat Bisa menyusun tulang Bukuno kamokulano liwu di atas kain putih / kain kafan berdasarkan urut-urutan tulang dari kepala hingga kaki, (8) kemudian proses pengkafanan dimana tulang Bukuno kamokulano liwu dibungkus dengan kain putih lalu diikat tiga ikatan yakni bagian atas kepala, tengah dan kaki, (9) sebelum tulang Bukuno kamokulano liwu ditutup dengan perahu, pejabat Bisa membacakan mantra-mantra, (10) sesudah dibacakan mantra-mantra oleh pejabat Bisa, tulang Bukuno kamokulano liwu ditutup dengan perahu, lalu pejabat imam membacakan doa (11) setelah pembacaan doa kemudian disekitar persemayaman dililitkan kain putih atau sisa dari kain kafan dijadikan kulambunya Bukuno kamokulano liwu.

Proses menyemayamkanBukuno

kamokulano liwu di Bukuno kamokulano liwudi atas tadi menjadikan suatu tradisi oleh masyarakat dengan tujuan agar tulang Bukuno kamokulano liwu maupun tempat persemayaman tetap bersih, hal ini menjadikan sistem kepercayaan oleh masyarakat. Hal ini sejalan dengan pendapatnya Liliweri (2014: 111) sistem kepercayaan itu beda dengan 
keyakinan religi yang biasanya dikodifikasi "kayakinan religi" mengacu pada keadaan mental dimana iman ditempatkan dalam kredo yang berhubungan dengan supranatural, suci, atau ilahi. Keadaan seperti ini memungkinkan berhubungan; keberadaan, karakteristik, dan adanya penyembahan kepada para dewa, (2) campur tangan ilahi atas alam dan kehidupan manusia, dan (3) nilai nilai praktek yang berpusat pada ajaran seorang spiritual.

\section{PENUTUP}

Berdasarkan hasil dan pembahasan di atas, maka dapat disimpulkan bahwa prosesi pelaksanaan ritual kakadiu Bukuno kamokulano liwu dilakukan dalam 5 (lima) tahapan.

Pertama, tahap persiapan, meliputi : (1) penyiapan segala keperluan berkaitan kelengkapan ritual yang dilakukan oleh Bonto wuntano liwu pada hari Kamis sehari sebelum pelaksanaan ritual kakadiu Bukuno kamokulano liwu; (2) Pada malam harinya tepatnya dimalam Jum'at pejabat Bonto atau Bisa berada di Daduwali untuk berdoa kepada sang pencipta agar pelaksanaan ritual pada pagi harinya berjalan aman dan tertib. (3) Keesokan harinya tepatnya dihari Jum'at pagi, para pejabat adat baik dari golongan saha,golongan hukuтu serta saha ho Bine berkumpul di Galampano Daduwali untuk bermusyawarah sekaligus pembagian tugas. Selain bermusyawarah dilakukan pula pengecekan kelengkapan ritual oleh pejabat Bisa, bila kelengkapan ritual sudah lengkap, maka dilanjutkan ke tahapberikutnya yaitu menuju tempat persemayaman Bukuno kamokulano liwu di tebing kantato.

Kedua, tahap menuju tempat mesemayamankan, meliputi (1) iring- iringan rombongan dari pembawa bendera hitam dan disusul pembawa gong dan gendang, (2) rombongan pejabat adat dimulai dari Bisa, golongan hukuтu imam, kemudian Bonto bersama pejabat adat lainnya disusul rombongan laki laki yang turut menyaksikan ritual, (3) disusul rombongan dari saha hoBine dimulai istri pejabat adat Bisa, istri pejabat hикити ітати, istri pejabat adat Bonto dan rombongan perempuan lainnya, (4) terkahir pembawa bendera putih sebagai penutup iring-iringan dan selama menuju tempat mengsemayamkan tulang bunyi gendang maupun gong diperdengarkan.

Ketiga, tahap ditempat persemayaman,meliputi : (1) pejabat adat Bisa memimpin sembah sebanyak 4 kali sambil mengucapkan "sombah waори iа waори "(2) Membersihkan diri dengan cara mencuci kaki, tangan dan muka sebelum menaiki/memanjat tebing tempat mengsemayamkan tulang, (3) setibanya didepan tulang, pejabat Bisa kembali lagi melakukan sembah sebanyak 4 kali sambil mengucapkan "somba waори іа waоpu ", (4) sesudah disembah, penutup tulang dari perahu maupun kain kafan dilepas.

Ketiga,tahap memandikan rangka. Dimulai dari : (1) tulang / rangka Bukuno Kamokulano Liwu dikremasi dengan santan kelapa dari tengkorak kepala hingga kaki, (2) diolesi dengan minyak kelapa, (3) disirami dengan air suci oe ngkolaki, (4) dikafani, (5) dibacakan mantra/do,a, (6) disemayamkan dalam perahu dan diberikan kulambu.

Keempat, tahap haroa, tahapan horoa sebagai tahap terakhir dalam pelaksanaan ritual kakadiu Bukuno kamokulano liwu, meliputi : (1) pembacaan doa selamat oleh imam dan (2) makan bersama. 


\section{DAFTAR PUSTAKA}

Agus, Bustanuddin. 2006.Agama dalam Kehidupan Manusia Pengantar Antropologi Agama. Jakarta: PT. Raja Raja Grafindo Persada

Alo Liliweri, 2014 Pengantar studi kebudayaan, penerbit Nusa Media Bandung, cetaka I agustus 2014.

Des Alwi, 2004 Sejarah Maluku, Banda Neira, ternate, Tidore dan Ambon penerbit Dian rakyat bekerjasama dengan yayasan warisan budaya Banda neira,2005

Francois Valentyn, 1724, Naskah yang berjudul "Oud en Nieuw Oost Indien " Dardrecht den, 24 Augufli 1724

Hadi, Y. Sumandiyo. 1999. Seni dalam Ritual Agama. Yogyakarta: Yayasan untuk Indonesia.

https://opini.id/opinistory/read-

5217/mengenal-agama-

kepercayaan-asli-nusantara,

Mengenal agama ( kepercayaan) asli Nusantara Opini.id.diakses tanggal 6 Oktober 2019.

https://www.goodnewsfromindonesia.id/

2017/05/27/5-agama-asli-

leluhurindonesia-yang-menjadi-

bukti-keberagaman. 5 agama Asli

leluhur Indonesia yang menjadi bukti keberagaman diakses tanggal 6 Oktober 2019.

I Nyoman Cau Arsana, 2014 ,Kosmologis Tetabun dalam Upcara Ngaben, Yogyakarta : Universitas Gajah Mada
I Wayan Chandara, 2018, Tradisi Ngeroras di desa Wirata Agung kecamatan Seputih Mataram kabupaten Lampung Tengah, Lampung :Universitas lampung.

Idwar Anwar, 2010 La Galigo turunnya Manusiapertama : Pustaka Sawerigading Arung Pustaka 2010.

Jan Vansina,2014 Tradisi Lisan sebagai Sejarah, penterjemah Astrid dkk, Jogyakarta : penerbit Ombak anggota Ikapi,

Koentjaraningrat, 1982 Ritus peralihan di Indonesia, penerbit dan percetakan PN Balai Pustaka, 1985

Koentjaraningrat, Manusia dan Kebudaya di Indonesia, Jakarta :penerbit Djambatan cetakan 20 tahun 2004

Koetjaraningrat. 1994. Kebudayaan Mentalitas dan Pembangunan. Jakarta: Gramedia Pustaka Utama.

Kuntowijoyo, 2006 Budaya dan Masyarakat.,edisi Paripurna, Yogyakarta : Tiara kencana 2016

La Niampe, La Aso, dan Sahrun, 2018 Muna Anaghaini,Yogyakarta : Oceania Pres.

La Ode Dika, 1971 Naskah sejarah dan kebudayaan Bombonawulu

Lagaligo, menurut naskah NBG 188 , Fachruddin Ambo Enre (ed) Edisi pertama tahun 1995, penerbit Djambatan dan KITLV. 
Lexy J. Moleong, 1988 Metodologi penelitian Kualitatif, edisi revisi terbitan Pt. Remaja Rosdakarya,Bandung 2017.

Ligtvoet, 1877 Beschrijving en Geschiedenis va Boeton.,Museum Granvanhagen, 18 Agustus 1887.

Lim imadudin dkk, 2018 Dunia Maritim Indonesia dalam perspektif sejarah, kementrian pendidikan dan kebudayaan balat pelestarian nilai budaya Makassar, penerbit pustaka Refleksi cetakan I, 2018.

Marianne W. Jorgensen dan Louise J. Phililips, 2010 Analisis Wacana, Teori dan Metode.Jakarta :Cetakan kelima Pustaka Pelajar.

Matulada,dkk $1990 \quad$ Sawerigading Folktale Sulawesi, Departemen Pendidikan dan Kebudayaan Direktorat Jendral kebudayaan , Jakarta Nopember 1990.

Modesta Rebeka, 2018 Fungsi Ritual Tari Ngayu dalam Upacara Nyobeng Suku Dayak Bidayuh desa Sebujit kabupaten Bekayang, Pontianak : Universitas Tanjungpura Pontianak

Nanang Martono, 2011 Sosiologi Perubahan Sosial, Perspektif Klasik, Modern, Posmodern, dan Poskolonial.Cetakan kedua, Jakarta : Pt. Rajagrafindo Persada.

Pujiastuti, Titik dan Tommy Christomy. 2011. Teks, Naskah, dan Kelisanan Nusantara: Festschrift untuk Prof. Achadiati Ikram.
Depok: Yayasan Pernaskahan Nusantara

Rais, Muhammad Amin. 2008. Agama dan Kearifan Lokal dalam Tantangan Global dalamKeberagaman Masyarakat Ujung Bone Sebuah Ritual "Addewatang Putta Sereng". Yogyakarta : Sekolah Pascasarjana UGM.

Rusmin Tumanggor, 2014 Ilmu Sosial dan Budaya Dasar, cetakan ketiga, Pustaka Pelajar.

Rene ve den Burg, 2013 A Grammer Langguage, SIL International.

Sahrun, 2013 Komodifikasi ritual Tuturangiana Andala pada masyarakat nelayan pulau Makassar kota Bua-bau provinsi Sulawesi Tenggara, Denpasar : Universitas Udayana Denpasar

Thomas Hylland Eriksen, 2001 Antropologi, Sosial dan Budaya, anggota Kapi, cetakan kedua, Cv. Titlan Galang Oritika.

Wililiard A.Hanna dan Des Alwi, 1990 Turbulent Times Past In Ternate and Todore, Yayasan Warisan dan Budaya Banda Neira, Fadjar Selamon Indonesia

Y.W Warta Jaya Winangun, 1990 Masyarakat bebas Struktur, Liminitas dan Komunitas menurut Victor Turner. 